\title{
Perspectivas de terapia celular em neurologia
}

\author{
Cell therapy perspectives in neurology
}

\author{
Fernando Onuchic $^{1}$, Chary Marquez Batista ${ }^{1}$, Guilherme Lepski ${ }^{1,2}$
}

Onuchic F, Batista CM, Lepski G. Perspectivas de terapia celular em neurologia/ Cell therapy perspectives in neurology. Rev Med (São Paulo). 2015 out.-dez.;94(4):230-8.

RESUMO: Neste artigo de revisão, buscamos ressaltar alguns dos avanços mais recentes na pesquisa sobre células-tronco em neurologia. Além disso, buscamos demonstrar a direta associação entre seu funcionamento e mecanismos de replicação, diferenciação e maturação, além da terapêutica celular de algumas doenças neurológicas. Abordamos a provável associação entre essas células indiferenciadas e a origem de alguns tumores malignos do $\mathrm{SNC}$, bem como os potenciais terapêuticos que o transplante das mesmas tem na medicina neurológica regenerativa. Por fim, concluímos que o entendimento e a pesquisa sobre esses mecanismos podem abrir portas para abordagens mais diretas e eficazes de diversas doenças atualmente incuráveis do sistema nervoso.

Descritores: Terapia baseada em transplante de células e tecidos; Medicina regenerativa; Células-tronco; Pesquisa com célulastronco; Doenças do sistema nervoso/diagnóstico; Neurologia.

\section{INTRODUÇÃO}

$\mathrm{O}$ uso de células-tronco representa uma alternativa promissora no futuro da medicina regenerativa, incluindo as doenças neurológicas, nas quais a perda de neurônios muitas vezes acarreta danos e sintomas irreversíveis ao paciente. Essas células possuem a capacidade tanto de se auto-renovar, gerando descendentes iguais, quanto de se diferenciar em células adultas, maduras e especializadas, participando, dessa forma, do crescimento, reparação e manutenção da homeostasia nos diferentes tecidos do organismo ${ }^{1}$.

\begin{abstract}
In this review, we sought to highlight some of the latest advances in stem-cell research in neurology. In addition, we demonstrated the direct association between its functioning and replication mechanisms, differentiation and maturation, and also the cell therapy involved in some neurological diseases. We discussed the possible association between these undifferentiated cells and the source of some malignant tumors of the CNS, as well as the therapeutic potential of transplanting these cells in neurologic regenerative medicine. Finally, we conclude that the understanding and research on these mechanisms may lead the way to more direct and effective approaches of several currently incurable diseases of the nervous system.
\end{abstract}

Keywords: Cell-and tissue-based therapy; Regenerative medicine; Stem cells; Steam cell research; Nervous system diseases/diagnosis; Neurology.

\footnotetext{
1. Departamento de Neurologia, Faculdade de Medicina da Universidade de São Paulo, São Paulo, Brasil.

2. Department of Neurosurgery, Eberhard-Karls University, Tuebingen, Germany.

Autor para correspondência: Prof. Dr. Guilherme A. Lepski. Neurocirurgião. Departamento de Neurologia. Universidade de São Paulo. Av. Dr. Arnaldo, 455. $4^{\circ}$ andar, sala 4220. Cerqueira Cesar. São Paulo, SP, Brasil. CEP: 01246-903. E-mail: lepski@usp.br
} 
capazes de originar qualquer tipo celular do organismo, incluindo os tecidos embrionários e extra-embrionários. Por sua vez, as células pluripotentes são capazes de gerar tipos celulares de todos os três folhetos germinativos (endoderma, mesoderma e ectoderma), porém não são capazes de gerar tecidos extra-embrionários, como a placenta e outros tecidos de suporte do feto. Finalmente, as células multipotentes são capazes de gerar diferentes tipos celulares apenas nos tecidos em que residem. Essas células estão presentes durante toda a vida embrionária e, em alguns tecidos, permanecem no organismo adulto, participando no reparo e regeneração de tecidos. As células multipotentes podem ser obtidas de diversas regiões do organismo, entre eles a medula óssea e o cordão umbilical ${ }^{1,2}$.

Por fim, vale destacar um novo tipo de célulatronco que vem ganhando espaço em pesquisas recentes: as células-tronco pluripotentes induzidas (IPS). Essas células nada mais são do que células já diferenciadas (por exemplo, fibroblastos, hepatócitos, células da medula óssea e células mucosas gástricas) que, por meio de ativação de genes específicos e fatores de transcrição, retornam ao seu estado pluripotente ${ }^{3}$. Os primeiros modelos de IPS foram obtidos por meio da expressão de Oct3/4, Sox2, Klf4 e c-Myc, introduzidos na célula na maioria das vezes através de vetores lentivirais. Embora possuam enorme capacidade de diferenciação, essas células apresentam alto potencial replicativo, o que condiciona frequentemente o aparecimento de teratomas. Assim sendo, seu uso para terapia celular em humanos ainda não foi aprovado ${ }^{4}$.

O desempenho das células-tronco depende de uma fina interação entre os fatores intrínsecos e os sinais extrínsecos do microambiente onde estão inseridas. $\mathrm{O}$ nicho microambiental é um compartimento anatômico especializado onde as células-tronco residem, formado por componentes celulares e moleculares que regulam a proliferação, diferenciação e sobrevivência dessas células. Entre os seus componentes, podemos citar fatores solúveis, proteínas da matriz extracelular, vasos sanguíneos e aferências neurais ${ }^{5}$. Quando células-tronco neurais (CTNs) são transplantadas em um micro-ambiente neurogênico favorável (por exemplo, no giro denteado hipocampal), se diferenciam e integram-se no tecido hospedeiro, ao passo que, se transplantadas num micro-ambiente nãoneurogênico (no corpo estriado), acabam por se degenerar e perecer ${ }^{6}$.

No sistema nervoso central, as CTNs e seus progenitores são comunmente referidos como células precursoras neurais $(\mathrm{CPNs})^{7}$. As CTNs possuem a capacidade de se diferenciar nas 3 linhagens neurais: neurônios, astrócitos e oligodendrócitos ${ }^{8}$. O processo de neurogênese (formação de neurônios a partir das CTNs) ocorre em todo o cérebro durante o período pré-natal, e continua ativo na vida adulta em duas regiões em especial: a zona subventricular (ZSV) e a camada subgranular do giro denteado do hipocampo (DG). A partir dessas regiões, neurônios adultos podem migrar para diferentes regiões do cérebro, dependendo do estímulo fisiológico ou patológico que venham a receber. Os neurônios da ZSV tendem a migrar majoritariamente para o bulbo olfatório, integrandose aos circuitos locais que compõem a memória olfativa9 ${ }^{9}$ Já as células do DG tendem a originar neurônios granulares, que se integram a circuitos hipocampais relacionados à memória declarativa ${ }^{10}$.

Nessas duas regiões, há um tipo especializado de astrócito em formato estrelado (positivo para GFAP e nestina), que pode ser considerado a verdadeira célulatronco neural fisiológica. Essas células dividem-se assimetricamente, gerando uma igual a si mesma e uma pequena e arredondada, chamada célula amplificadora transitória (CAT). As CAT, por sua vez, se dividem em taxas elevadas, produzindo neurônios jovens denominados neuroblastos, que migram para seu sítio definitivo no SNC durante as etapas finais de diferenciação ${ }^{11}$.

\section{Células-tronco e patogênese em neurologia}

Elucidar o complexo processo de desenvolvimento, divisão e maturação das células indiferenciadas do SNC até originarem as diferentes linhagens neurais (neurônio, astrócito e oligodendrócito) tem se revelado fundamental para explicar a origem de diversas doenças, dentre elas o câncer.

Um exemplo clássico disso é o glioblastoma multiforme (GBM). Essa neoplasia, que é a mais comum dentre os tumores primários do cérebro, se caracteriza por ser altamente maligna e agressiva, com sobrevida média de 1,5 anos a despeito do tratamento multidisciplinar com cirurgia e radio/quimioterapia ${ }^{12,13}$. Além disso, apresenta padrão celular bastante heterogêneo, com diversas populações celulares que diferem em função e fenótipo ${ }^{14}$. Contudo, sua patogênese ainda é incerta.

Uma teoria que encontra eco em estudos mais recentes é a hipótese de que o tumor provém de CSCs (cancer stem cells), como resultado de um processo de diferenciação anômala de CTN endógenas. Essa população de CSCs guardaria propriedades comuns a células-tronco normais. Além disso, em função de seu perfil de resistência a anóxia e a radio/quimioterapia, essas células-tronco vêm sendo implicadas na resistência e recorrência do processo neoplásico ${ }^{15}$.

Essa teoria teria profundas implicações na maneira como os tumores são abordados na prática clínica, bem como seus potenciais tratamentos. Afinal, se esse subgrupo com características de CT é capaz de gerar e repopular um tumor maligno, um tratamento eficaz exigiria a eliminação total dessa população celular. Dessa forma, torna-se essencial entender melhor a fisiologia e as especificidades dessas células. Além disso, é necessário descobrir sua identidade funcional no cérebro humano, uma questão que se mantém controversa na literatura. Atualmente, a teoria 
mais acreditada é que as CSCs seriam oriundas de células indiferenciadas do SNC.

O marcador CD133 é uma das evidências que embasam essa teoria: bastante expresso em CTNs fisiológicas, é encontrado também em CSCs de glioblastoma. Assim, tornou-se um marcador bastante utilizado para esse tipo tumoral, partindo-se da observação de que um pequeno contingente de células CD133+ é capaz de originar GBMs em ratos, ao passo que células CD133- não o fazem ${ }^{16}$.

Outra evidência de que as CSCs provêm de células indiferenciadas é o microambiente no qual o tumor cresce: chamado de nicho perivascular, ele é composto por diversos tipos celulares (astrócitos, células endoteliais, macrófagos, microglia e células tumorais) e se assemelha bastante ao ambiente no qual as células fisiológicas crescem ${ }^{17}$. Esse nicho é em grande parte responsável pela sobrevivência do tumor, ao garantir o aporte necessário de nutrientes e oxigênio ${ }^{18}$, além de proteger as células tumorais de agressões ambientais (o que explica em parte a resistência desse tipo tumoral à quimioterapia convencional $)^{18}$. Vale ressaltar que as próprias células cancerígenas também atuam na modificação desse nicho, tornando-o mais propício ao seu desenvolvimento por meio da secreção de fatores angiogênicos (por exemplo, o VEGF) ${ }^{19}$.

Assim como no desenvolvimento fisiológico de células indiferenciadas, os processos de sinalização celular são essenciais para compreender a patogênese dessas neoplasias. Alguns estudos comprovam que alterações em vias de proliferação e maturação neuronal, bem como na expressão de fatores de transcrição, podem influenciar nas características clínicas e histológicas da doença, e podem estar diretamente envolvidas com a sua fisiopatologia. Um exemplo é a via de sinalização Notch: quando ativada, ela induz auto-renovação das CTNs; quando inibida, ela permite diferenciação dessas células em neurônios ${ }^{20}$. Estudos já notificaram uma hiper ativação dessa via em GSCs, o que explicaria uma replicação excessiva de células tumorais com características de células-tronco ${ }^{21}$. Além disso, a via parece estar envolvida com a resistência que esses tumores apresentam a quimioterapia ${ }^{22}$.

Outra via que parece estar alterada na doença é a da BMP. Essa família de citocinas atua sobre as CTNs, regulando sua proliferação, diferenciação e apoptose. Sobre as CSCs, parece que a BMP inibe seu crescimento e replicação ${ }^{23}$. Assim, há indícios de que a BMP seja eficaz para reduzir o tumor em modelos animais, podendo se provar a longo prazo um tratamento eficaz em humanos ${ }^{24}$.

Em relação a fatores de transcrição, um exemplo que pode estar envolvido na patogênese da doença é o PRC1. Em células normais, atua como supressor de tumores e como mantenedor da função normal nas CTNs. Assim, quando esse mecanismo é silenciado, ocorre uma disfunção de células-tronco, que altera sua função e pode levar a um fenótipo cancerígeno. Não à toa, está relacionado a fenótipos mais agressivos de $\mathrm{GBM}^{25}$.
Outro exemplo seria o fator Olig2. É um mecanismo bastante ativo no desenvolvimento embrionário e em tumores em crescimento, e está envolvido com a supressão do crescimento promovida pelo p53 ${ }^{26}$. Assim, seu silenciamento está diretamente associado com uma tumorigênese menos agressiva, bem como menores taxas de crescimento tumoral ${ }^{27}$.

Por fim, vale lembrar outras neoplasias menos comuns que o GBM, mas que também parecem estar envolvidas com alguma disfunção na maturação de células indiferenciadas. Um exemplo é o tumor neuroectodérmico primitivo (PTEN), cuja correlação direta com a mutação dos genes p53, Rb e PTEN em CTNs da ZSV foi comprovada em modelos animais ${ }^{28}$.

Outro exemplo seria o meduloblastoma, tumor que atinge o cerebelo ainda na infância e que é altamente maligno. Essa neoplasia parece se originar de precursores indiferenciados de neurônios granulares do cerebelo, que se proliferam indiscriminadamente após mutações em vias sinalizatórias como Shh, Notch e WNT ${ }^{29}$.

Dessa forma, torna-se evidente o papel central que o processo de diferenciação das CTNs em células maduras executa na patogênese dessas doenças. Logo, fica clara a necessidade de melhor compreensão desses mecanismos, a fim de que possamos tratar e prevenir melhor essas graves afecções do SNC.

\section{Células-tronco exógenas e o tratamento de doenças neurológicas}

Durante muito tempo, a neurologia se baseou no princípio de que, após o desenvolvimento pré-natal do SNC, esse seria um sistema totalmente imutável, apenas com células neuronais plenamente diferenciadas. Dessa forma, interpretava-se uma perda de neurônios, aguda ou crônica, como um dano irreversível, incapaz de ser resolvido ou até mesmo minimizado pelo próprio SNC.

Estudos clássicos de Santiago Ramón y Cajal, utilizando técnicas limitadas de coloração tecidual, não demonstraram a existência de figuras mitóticas em neurônios no cérebro adulto, embora tenha evidenciado a capacidade dos neurônios de regenerarem seus axônios e formar novas conexões após lesões do $\mathrm{SNC}^{30}$. Contudo, em 1992, Reynold e Weiss ${ }^{31}$ demonstraram pela primeira vez a existência de neurogênese no cérebro adulto. Depois disso, inúmeras evidências da plasticidade do sistema nervoso surgiram, e o neurônio passou a ser visto como uma célula capaz de se adaptar e sofrer algumas modificações, mesmo após seu pleno desenvolvimento ${ }^{32}$.

Além disso, estudos mais recentes apontam para uma nova informação: embora de maneira significativamente menos intensa que no período pré-natal, o processo de diferenciação de CTNs em neurônios maduros ainda se mantém ativo no cérebro adulto. Tal processo está continuamente envolvido em processos fisiológicos 
(como a memória e a sensibilidade olfatória), e pode ser amplificado diante de agressões externas ${ }^{33}$.

Entretanto, do ponto de vista clínico, tais descobertas ainda têm pouca aplicabilidade. Apesar de presente, a neurorregeneração pós-lesões ainda é pouco significativa, de modo que o prognóstico de afecções recorrentes no SNC (como AVCs, lesões cerebrais e medulares traumáticas e doenças neurodegenerativas) continua ruim. Dessa forma, torna-se essencial a investigação de novas estratégias para essas condições clínicas, de modo que se consiga potencializar a regeneração das células do sistema nervoso.

Diante desse cenário, a terapia celular com células indiferenciadas parece uma ideia promissora. Uma possibilidade seria o transplante exógeno de células, extraídas de organismos ainda em estágios prévios de maturação (células-tronco embrionárias e fetais), a fim de simular o processo fisiológico de diferenciação e regenerar parte do tecido lesado. Conforme diversos estudos revelam, essa estratégia tem se mostrado promissora em diversas doenças, mas ainda enfrenta diversos desafios.

Um exemplo de afeç̧ão neurológica que tem sido alvo de diversos estudos é a doença de Parkinson. Ela se caracteriza por ser uma doença progressiva, hipocinética e neurodegenerativa, com sintomas motores como bradicinesia, rigidez, acinesia, instabilidade postural e tremor de repouso. Tais sintomas estão associados à perda de neurônios dopaminérgicos (DA) na substância negra ${ }^{34}$.

Estudos clássicos de Bjorklund e Stenevi ${ }^{35}$ abordaram a possibilidade de reinervação do estriado por meio de transplantes de mesencéfalo fetal. Anos depois, Lindvall reportou pela primeira vez melhora clínica em pacientes com doença de Parkinson transplantados da mesma forma ${ }^{36}$. Estudos prospectivos e controlados subsequentes, no entanto, mostraram resultados insatisfatórios, principalmente às custas de discinesias induzidas pelos enxertos. Isso provavelmente se deve a uma série de fatores que possivelmente não foram estudados a fundo, dentre eles: a quantidade de tecido necessária para obter resultado, a reação imunológica local, o local do cérebro escolhido para o transplante e os possíveis efeitos colaterais que podem decorrer ${ }^{37,38}$. Outro estudo abordou, além dessas questões, a importância de neurônios serotoninérgicos, que ao induzir uma hiper-inervação do transplante, asseguram a atividade funcional e geram locais para o armazenamento e liberação de dopamina, o que reduziria os efeitos farmacológicos do tratamento medicamentoso, reduzindo assim os riscos de discinesia ${ }^{39}$.

Contudo, apesar dos estudos na área, a neurorestauração ainda não foi incorporada no esquema terapêutico da doença. $O$ que sabemos é que a doença não se resume apenas a uma perda de neurônios DA, mas também envolve outros fatores, como predisposição genética, uma condição neuro-inflamatória local, a influência de agregados de proteínas e a participação de outras células neurais ${ }^{40}$. Dessa forma, ainda seria necessário preencher vários critérios básicos antes de partir para outros ensaios clínicos, dentre eles: re-programação celular para se impedir ou retardar a apoptose, co-transplante de tipos célulares capazes de inibir as discinesias, recrutamento dos pacientes mais aptos a responderem à terapia celular, desenvolvimento de métodos capazes de se aumentar a diferenciação neuronal dentro do graft, dentre outros desafios. Nesse último quesito, um trabalho recente de nosso grupo demonstrou de maneira pioneira que a terapia de estimulação cerebral crônica, seguido do transplante celular, aumenta o poder de eficácia dos transplantes e aumenta a geração de células dopaminérgicas no enxerto ${ }^{41}$.

Outro tipo de afecção bastante estudada são as doenças desmielinizantes. Essas síndromes se caracterizam pela perda de mielina nos neurônios, normalmente por uma série de pequenas reações inflamatórias locais. Exemplos são a esclerose múltipla, a mielite transversa, a doença de Devic, a leucoencefalopatia multifocal progressiva, a neurite óptica, dentre outras.

Uma solução que possivelmente obteria bons resultados seria o transplante de células produtoras de mielina (por exemplo, células de Schwann). Contudo, esse tipo celular apresenta grandes dificuldades de ser criado e expandido in vitro, o que representa um entrave à sua utilização na terapia celular. Assim, a estratégia mais usada em estudos da área tem sido o transplante de CNPs (células ainda indiferenciadas, mas já comprometidas com a linhagem neural) adultas. Em um modelo experimental de encefalomielite, por exemplo, CNPs adultas apresentaram boa migração e direcionamento, indo em maior número para locais desmielinizados. Além disso, foram capazes de se diferenciar em neurônios, oligodendrócitos e astrócitos, e diminuíram a formação de cicatriz glial. Isso indica que esse tipo celular tem um fenótipo principalmente neurorestaurador in vivo, promovendo restauração onde ocorre neurodegeneração. Ao mesmo tempo, ele continua indiferenciado onde ocorre neuroinflamação, mantendo seu fenótipo e sua capacidade proliferativa, enquanto diminui os danos no tecido, reduzindo a resposta inflamatória $\mathrm{TH} 1$, que contribui com a destruição da mielina ${ }^{42}$.

Contudo, apesar desses resultados positivos, ainda restam dúvidas em relação à interação entre células transplantadas com o tecido hospedeiro, a melhor via de administração, e a segurança e viabilidade dessas intervenções em humanos.

Outras afecções que vem apresentando alguns resultados promissores são as lesões traumáticas, tanto cerebrais (LCT) quanto medulares (LMT). Ambas são lesões bastante frequentes em nosso meio, e têm entre suas principais causas os acidentes automotores, a violência urbana e as quedas não intencionais ${ }^{43}$. Além disso, possuem alto custo social, devido aos custos da reabilitação e por acometerem principalmente adultos jovens, que ainda estão em fase produtiva da vida. Dependendo de sua extensão, intensidade e topografia, podem levar a grandes perdas 
neuronais e provocar graves sintomas ${ }^{44}$.

Em um estudo com animais submetidos à LCT foi revelado que, após o transplante de NPCs no estriado, há maior sobrevivência a longo prazo, bem como recuperação motora, sem formação de tumores. Contudo, a imuno histoquímica não revelou marcadores neuronais, apenas oligodendrogliais ${ }^{45}$. Em contraste, o transplante para cérebros sadios resultou em neurônios maduros funcionais ${ }^{46}$. Além disso, células-tronco neurais fetais, quando transplantadas para o entorno da área lesada, provocam melhoria motora, mas não $\operatorname{cognitiva}{ }^{47}$. Já quando transplantadas para o hipocampo, ocorre melhorias cognitivas, mas não motoras ${ }^{48}$.

Em outros trabalhos, o transplante de célulastronco embrionárias pré-diferenciadas em precursores neurais e gliais apresentou grandes melhoras sensoriais e motoras, mas não cognitiva ${ }^{49}$; já o transplante de neurônios GABAérgicos levou a uma maior recuperação sensório-motora, o que não foi observado no transplante de astrócitos ${ }^{50}$. Outro achado interessante desses estudos foi que algumas células transplantadas migraram para a região $\mathrm{DG}$, que atrairia as células e auxiliaria na sua diferenciação ${ }^{51}$. Assim, esses resultados sugerem que o local de implante e a especificidade do tecido transplantado influenciam bastante a recuperação funcional e a diferenciação celular ${ }^{52}$.

Em relação à LMT, as células-tronco provenientes da bainha olfativa (OECs) parecem ser ótimas candidatas para o transplante celular nessa doença. Afinal, além de representarem uma possibilidade de transplante endógeno e possuírem diversas características em comum com as CTEs, essas células possuem alta capacidade de mielinização, promoção da regeneração axonal e promoção da capacidade endógena das células de Schwann para invadir o local lesionado, criando assim um ambiente favorável à regeneração axonal ${ }^{53}$.

Essas capacidades motivaram uma série de ensaios clínicos. Um estudo piloto relatou melhora de escores ASIA sensoriais e motores, mudanças no controle muscular voluntário, melhora nas funções autonômicas de intestino e bexiga, e redução da cavidade da lesão nos pacientes transplantados. Contudo, vale ressaltar que houve efeitos adversos em três pacientes com episódios de redução no escore ASIA e aumento da dor lombar ${ }^{53}$. Outro estudo realizado pelo mesmo grupo indicou melhorias dos sintomas também em pacientes com LMT crônica (há mais de um ano $)^{54}$. Por fim, outro ensaio clínico relacionado sugeriu que resultados promissores podem ser alcançados combinando o transplante de OECs e fragmentos de medula espinhal fetal, levando a uma maior recuperação nas funções motoras, sensoriais e autonômicas ${ }^{55}$.

Por fim, vale ressaltar um estudo de 2005, no qual foi comprovada a eficácia do transplante exógeno de NPCs em animais submetidos tanto a LCT quanto a LMT. Além das células terem sobrevivido e proliferado em quantidade razoável, o estudo comprovou, por meio de marcadores imuno histoquímicos, que o fenótipo final das células transplantadas variou conforme a lesão. Além disso, o uso de vetores lentivirais, para permitir o rastreamento das células após o transplante, abriu espaço para investigar outras possibilidades terapêuticas associadas, como, por exemplo, a possibilidade de alterações gênicas para se induzir uma hiper-expressão de neurotrofinas ${ }^{56}$.

Assim, fica evidente o grande potencial terapêutico que células indiferenciadas exógenas podem ter nessas doenças; contudo, novamente, a compreensão dos mecanismos celulares e moleculares por trás do processo, bem como a interação do transplante com o microambiente local, parecem ser essenciais para que haja um avanço nesse sentido e um efetivo uso na clínica.

\section{Uma nova alternativa: células-tronco endógenas}

Apesar dos resultados promissores das pesquisas com células-tronco exógenas, esse campo ainda esbarra em alguns entraves, sendo os principais: respostas imunitárias deflagradas contra as células (que provêm de outros organismos e podem ser interpretadas como antígenos), efeitos colaterais consequentes e questões de ordem ética, pois essas células são extraídas de fetos ou embriões. Nesse contexto, surgiu a ideia do transplante celular autólogo: realizar transplantes a partir de células endógenas, que seriam extraídas de tecidos do próprio indivíduo, reduzindo significativamente esses problemas. Assim, vamos abordar duas alternativas nesse sentido, que têm sido alvo de estudos em neurologia: células-tronco adultas (CTAs) e células-tronco pluripotentes induzidas (IPS).

As CTAs são células multipotentes, que podem ser encontradas em diversos tecidos do organismo adulto. É um tipo celular que apresenta diversas vantagens no transplante: podem ser extraídas de vários tecidos do organismo adulto, facilitando a extração para o paciente e reduzindo seus efeitos colaterais; podem ser usadas para transplante celular autólogo; e não apresentam restrições éticas ao seu uso, pois sua extração não envolve destruição de embriões ou fetos ${ }^{2}$.

Assim como outros tipos de células-tronco, as CTAs são capazes de promover regeneração tecidual por diversos mecanismos. Além de promover repovoamento do tipo celular perdido (seja se diferenciando diretamente nele, ou atraindo CTs no entorno para fazer isso), elas também apresentam potencial imuno-modulador: alguns estudos já comprovaram que elas são capazes de inibir o processo inflamatório local secundário a uma lesão, e estimular a regeneração tecidual ${ }^{57}$. CT mesenquimais, por exemplo, são capazes de mudar o fenótipo dos macrófagos ao serem transplantadas para um tecido lesado, inibindo sua atividade pró-inflamatória e estimulando sua atividade pró-regenerativa $^{57,58}$.

Contudo, a utilização in vivo de células-tronco 
sempre esbarra em dificuldades variadas. No caso das células-tronco adultas, deve-se considerar a baixa porcentagem que elas representam nos tecidos nos quais estão presentes, o que leva pesquisadores a expandi-las através de substâncias que estimulem seu crescimento (por exemplo, G-CSF para células hematopoiéticas da medula óssea) $)^{59}$.

Outro fator importante a se levar em conta é a senescência celular associada à expansão in vitro (necessária após a sua extração). Esse processo é bastante descrito na literatura, e ocorre devido a uma série de mecanismos celulares e moleculares pouco elucidados, dos quais o principal é a ação das telomerases, que encurtam os telômeros do DNA celular a cada replicação, reduzindo sua capacidade proliferativa ${ }^{60}$. Além disso, devemos considerar a senescência do organismo do qual retiramos as células: em tecidos mais envelhecidos, há perda de função celular, potência e capacidade replicativa das células, ao mesmo tempo em que ocorre acúmulo de mutações somáticas. No caso do SNC, isso se reflete em perda neuronal, mau funcionamento celular, menor capacidade de regeneração frente a lesões, menor capacidade de aprendizado, alterações no microambiente tecidual, dentre outras consequências ${ }^{61}$.

IPS, por sua vez, ainda estão em fase de desenvolvimento e aprimoramento para ampliação do seu uso em ensaios clínicos. Ainda permanece como objetivo importante o aumento de sua biosegurança após a manipulação genética que condiciona retorno ao estado pluripotente. Já se cogita utilizar esse tipo celular no tratamento de algumas doenças neurológicas, em especial as degenerativas (doença de Parkinson, Huntington e esclerose lateral amiotrófica) ${ }^{62}$. Dentre suas vantagens, estariam: a ausência de questões éticas relacionadas, uma vez que não exigiriam a destruição de tecido fetal ou embrionário, e a ausência de imunossupressão após o transplante, uma vez que o transplante seria autólog $0^{63}$.

\section{REFERÊNCIAS}

1. Hosseinkhani M, Shirazi R, Rajaei F, Mahmoudi M, Mohammadi N, Abbasi M. Engineering of the embryonic and adult stem cell niches. Iran Red Crescent Med J. 2013;15(2):83-92. doi: 10.5812/ircmj.7541.

2. Bongso A, Richards M. History and perspective of stem cell research. Best Pract Res Clin Obstet Gynaecol. 2004;18(6):827-42. doi:10.1016/j.bpobgyn.2004.09.002.

3. Hochedlinger K, Plath K. Epigenetic reprogramming and induced pluripotency. Development. 2009;136(4):509-23. doi: $10.1242 /$ dev.020867..

4. Yamanaka S. A fresh look at iPS cells. Cell. 2009;137(1):13-7. doi: 10.1016/j.cell.2009.03.034.

5. Lander AD, Kimble J, Clevers H, Fuchs E, Montarras D, Buckingham M, Calof AL, Trumpp A, Oskarsson T. What
Contudo, seu uso em humanos ainda é muito restrito, principalmente devido aos riscos que essa terapia traria. A ocorrência de teratomas é um risco evidenciado por uma série de estudos ${ }^{63-65}$; faz-se necessário compreender melhor os riscos tumorigênicos antes de partirmos para ensaios clínicos e testes em humanos. Basicamente, o aumento do potencial de diferenciação celular está diretamente relacionado a um maior potencial replicativo, o que por sua vez favorece a degeneração maligna.

Alguns estudos já foram desenvolvidos no sentido de compreender as razões desse efeito, e tentar diminuílo. Por exemplo, um trabalho recente buscou reduzir a carcinogênese dessas células por meio da inserção dos genes indutores de pluripotência em lócus específicos do genoma humano, que sejam mais seguros contra esses eventos (por exemplo, a região AAVS1, do cromossomo 19) ${ }^{66}$. Outro trabalho busca compreender se IPS são necessariamente carcinogênicas, e quais são as associações entre elas e as células neoplásicas ${ }^{67}$. Contudo, fica evidente que esse é um grande entrave a ser superado, caso desejemos utilizar no futuro esse tipo celular para transplantes bem sucedidos.

\section{CONCLUSÃo}

Por fim, podemos concluir que avanços significativos no estudo de células-tronco em neurologia e processos de neurogênese abriram caminho tanto para a compreensão da fisiopatologia de doenças (por exemplo, os GBMs), quanto para possíveis tratamentos futuros para outras doenças. Assim, torna-se realista imaginar que esses conhecimentos adentrem a área clínica em um futuro próximo, na forma de terapias mais novas e eficazes para doenças até então incuráveis. Contudo, antes que avancemos para ensaios clínicos, é necessário compreendermos os mecanismos celulares e moleculares por trás desses processos, bem como a interação das células-tronco com o micro-ambiente hospedeiro.

does the concept of the stem cell niche really mean today? BMC Biol. 2012;10:19. doi: 10.1186/1741-7007-10-19.

6. Lepski G, Jannes CE, Strauss B, Marie SK, Nikkhah G. Survival and neuronal differentiation of mesenchymal stem cells transplanted into the rodent brain are dependent upon microenvironment. Tissue Eng Part A. 2010;16(9):2769-82. doi: 10.1089/ten.TEA.2009.0686.

7. McKay R. Stem cells in the central nervous system. Science. 1997;276(5309):66-71. doi: 10.1126/science.276.5309.66.

8. Gage FH. Mammalian neural stem cells. Science. 2000;287(5457):1433-8. doi: 10.1126/science.287.5457.1433.

9. Petreanu L, Alvarez-Buylla A. Maturation and death of adult-born olfactory bulb granule neurons: role of olfaction. J Neurosci. 2002;22(14):6106-13. 
10. Ide Y, Fujiyama F, Okamoto-Furuta K, Tamamaki N, Kaneko T, Hisatsune T. Rapid integration of young newborn dentate gyrus granule cells in the adult hippocampal circuitry. Eur J Neurosci. 2008;28(12):2381-92. doi: 10.1111/j.14609568.2008.06548.x.

11. Ming GL, Song H. Adult neurogenesis in the mammalian central nervous system. Annu Rev Neurosci. 2005;28:223-50. doi: 10.1146/annurev.neuro.28.051804.101459.

12. Laws ER, Parney IF, Huang W, Anderson F, Morris AM, Asher A, Lillehei KO, Bernstein M, Brem H, Sloan A, Berger MS, Chang S, Glioma Outcomes Investigators. Survival following surgery and prognostic factors for recently diagnosed malignant glioma: data from the Glioma Outcomes Project. J Neurosurg. 2003;99(3):467-73. Available from: http://thejns. org/doi/full/10.3171/jns.2003.99.3.0467.

13. Shahar T, Nossek E, Steinberg DM, Rozovski U, Blumenthal DT, Bokstein F, Sitt R, Freedman S, Corn BW, Kanner AA, Ram Z. The impact of enrollment in clinical trials on survival of patients with glioblastoma. J Clin Neurosci. 2012;19(11):1530-4. doi: 10.1016/j.jocn.2012.04.005.

14. Friedmann-Morvinski D. Glioblastoma heterogeneity and cancer cell plasticity. Crit Rev Oncog. 2014;19(5):327-36. doi: $10.1615 /$ CritRevOncog.2014011777.

15. Singh SK, Hawkins C, Clarke ID, Squire JA, Bayani J, Hide T, Henkelman RM, Cusimano MD, Dirks PB. Identification of human brain tumour initiating cells. Nature. 2004;432(7015):396-401. http://dx.doi.org/10.1038/ nature 03128 .

16. Jin F, Zhang R, Feng S, Yuan CT, Zhang RY, Han GK, Li GH, Yu XZ, Liu Y, Kong LS, Zhang SL, Zhao L. Pathological features of transplanted tumor established by CD133 positive TJ905 glioblastoma stem-like cells. Cancer Cell Int. 2015;15:60.

17. Charles NA, Holland EC, Gilbertson R, Glass R, Kettenmann H. The brain tumor microenvironment. Glia. 2012;60(3):50214. doi: http://dx.doi.org/10.1002/glia.21264.

18. Folkerth RD. Histologic measures of angiogenesis in human primary brain tumors. Cancer Treat Res. 2004;117:79-95. doi: 10.1007/978-1-4419-8871-3 4.

19. Lathia JD, Heddleston JM, Venere M, Rich JN. Deadly teamwork: neural cancer stem cells and the tumor microenvironment. Cell Stem Cell. 2011;8(5):482-5.

20. Imayoshi I, Sakamoto M, Yamaguchi M, Mori K, Kageyama R. Essential roles of Notch signaling in maintenance of neural stem cells in developing and adult brains. J Neurosci. 2010;30(9):3489-98. doi: 10.1523/ JNEUROSCI.4987-09.2010.

21. Wang K, Wu X, Wang J, Huang J. Cancer stem cell theory: therapeutic implications for nanomedicine. Int J Nanomed. 2013;8:899-908. doi: 10.2147/IJN.S38641.

22. Fan X, Khaki L, Zhu TS, Soules ME, Talsma CE, Gul N, Koh C, Zhang J, Li YM, Maciaczyk J, Nikkhah G, Dimeco F, Piccirillo S, Vescovi AL, Eberhart CG. NOTCH pathway blockade depletes CD133-positive glioblastoma cells and inhibits growth of tumor neurospheres and xenografts. Stem Cells. 2010;28(1):5-16. doi: 10.1002/stem.254.

23. Lim DA, Tramontin AD, Trevejo JM, Herrera DG, GarciaVerdugo JM, Alvarez-Buylla A. Noggin antagonizes BMP signaling to create a niche for adult neurogenesis. Neuron. 2000;28(3):713-26. doi: 10.1016/S0896-6273(00)00148-3.

24. Piccirillo SG, Reynolds BA, Zanetti N, Lamorte G, Binda E, Broggi G, Brem H, Olivi A, Dimeco F, Vescovi AL. Bone morphogenetic proteins inhibit the tumorigenic potential of human brain tumour-initiating cells. Nature. 2006;444(7120):761-5. doi: 10.1038/nature05349.

25. Gargiulo G, Cesaroni M, Serresi M, de Vries N, Hulsman D, Bruggeman SW, Lancini $C$, van Lohuizen M. In vivo RNAi screen for BMI1 targets identifies TGF-beta/BMP-ER stress pathways as key regulators of neural- and malignant gliomastem cell homeostasis. Cancer Cell. 2013;23(5):660-76. doi: 10.1016/j.ccr.2013.03.030.

26. Meijer DH, Kane MF, Mehta S, Liu H, Harrington E, Taylor CM, Stiles CD, Rowitch DH. Separated at birth? The functional and molecular divergence of OLIG1 and OLIG2. Nature Rev Neurosci. 2012;13(12):819-31. doi: 10.1038/ nrn3386.

27. Tu Y, Gao X, Li G, Fu H, Cui D, Liu H, Jin W, Zhang Y. MicroRNA-218 inhibits glioma invasion, migration, proliferation, and cancer stem-like cell self-renewal by targeting the polycomb group gene Bmil. Cancer Res. 2013;73(19):6046-55. doi: 10.1158/0008-5472.CAN-130358 .

28. Jacques TS, Swales A, Brzozowski MJ, Henriquez NV, Linehan JM, Mirzadeh Z, C OM, Naumann H, Alvarez-Buylla A, Brandner S. Combinations of genetic mutations in the adult neural stem cell compartment determine brain tumour phenotypes. EMBO J. 2010;29(1):222-35. doi: 10.1038/ emboj.2009.327.

29. Rodini CO, Suzuki DE, Nakahata AM, Pereira MC, Janjoppi L, Toledo SR, Okamoto OK. Aberrant signaling pathways in medulloblastomas: a stem cell connection. Arq Neuropsiquiatr. 2010;68(6):947-52. http://dx.doi.org/10.1590/ S0004-282X2010000600021.

30. Berciano J, Lafarga M, Berciano M. Santiago Ramon y Cajal. Neurologia. 2001;16(3):118-21.

31. Reynolds BA, Weiss S. Generation of neurons and astrocytes from isolated cells of the adult mammalian central nervous system. Science. 1992;255(5052):1707-10. Available from: http://www.sciencemag.org/content/255/5052/1707.long.

32. Paredes MF, Sorrells SF, Garcia-Verdugo JM, Alvarez-Buylla A. Brain size and limits to adult neurogenesis. J Comp Neurol. 2015. doi: 10.1002/cne.23896.

33. Aimone JB, Li Y, Lee SW, Clemenson GD, Deng W, Gage FH. Regulation and function of adult neurogenesis: from genes to cognition. Physiol Rev. 2014;94(4):991-1026. doi: 10.1152/physrev.00004.2014.

34. Fox SH, Katzenschlager R, Lim SY, Ravina B, Seppi K, Coelho M, Poewe W, Rascol O, Goetz CG, Sampaio C. The 
movement disorder society evidence-based medicine review update: treatments for the motor symptoms of Parkinson's disease. Mov Disord. 2011;26(Suppl 3):S2-41. doi: 10.1002/ mds. 23884 .

35. Bjorklund A, Stenevi U. Reconstruction of the nigrostriatal dopamine pathway by intracerebral nigral transplants. Brain Res. 1979;177(3):555-60. doi: 10.1016/0006-8993(79)904724.

36. Lindvall O. Treatment of Parkinson's disease using cell transplantation. Philos Trans R Soc Lond B Biol Sci. 2015;370(1680). doi: 10.1098/rstb.2014.0370.

37. Freed CR, Greene PE, Breeze RE, Tsai WY, DuMouchel W, Kao R, Dillon S, Winfield H, Culver S, Trojanowski JQ, Eidelberg D, Fahn S. Transplantation of embryonic dopamine neurons for severe Parkinson's disease. N Engl J Med. 2001;344(10):710-9. doi: 10.1056/NEJM200103083441002.

38. Olanow CW, Goetz CG, Kordower JH, Stoessl AJ, Sossi V, Brin MF, Shannon KM, Nauert GM, Perl DP, Godbold J, Freeman TB. A double-blind controlled trial of bilateral fetal nigral transplantation in Parkinson's disease. Ann Neurol. 2003;54(3):403-14. doi: 10.1002/ana.10720.

39. Winkler C, Kirik D, Bjorklund A. Cell transplantation in Parkinson's disease: how can we make it work? Trends Neurosci. 2005;28(2):86-92. doi: 10.1016/j.tins.2004.12.006.

40. Allan LE, Petit GH, Brundin P. Cell transplantation in Parkinson's disease: problems and perspectives. Curr Opin Neurol. 2010;23(4):426-32. doi: 10.1097/ WCO.0b013e32833b1f62.

41. Furlanetti LL, Cordeiro JG, Cordeiro KK, Garcia JA, Winkler C, Lepski GA, Coenen VA, Nikkhah G, Dobrossy MD. Continuous high-frequency stimulation of the subthalamic nucleus improves cell survival and functional recovery following dopaminergic cell transplantation in rodents. Neurorehabil Neural Repair. 2015; 29(10):1001-12. doi: $10.1177 / 1545968315581419$.

42. Pluchino S, Zanotti L, Rossi B, Brambilla E, Ottoboni L, Salani G, Martinello M, Cattalini A, Bergami A, Furlan R, Comi G, Constantin G, Martino G. Neurosphere-derived multipotent precursors promote neuroprotection by an immunomodulatory mechanism. Nature. 2005;436(7048):266-71. doi: 10.1038/ nature 03889

43. DeVivo MJ. Causes and costs of spinal cord injury in the United States. Spinal cord. 1997;35(12):809-13. doi: 10.1097/00005392-199812010-00135.

44. Ma VY, Chan L, Carruthers KJ. Incidence, prevalence, costs, and impact on disability of common conditions requiring rehabilitation in the United States: stroke, spinal cord injury, traumatic brain injury, multiple sclerosis, osteoarthritis, rheumatoid arthritis, limb loss, and back pain. Arch Phys Med Rehabil. 2014;95(5):986-95 e1. doi: 10.1016/j. apmr.2013.10.032.

45. Shear DA, Tate MC, Archer DR, Hoffman SW, Hulce VD, Laplaca MC, Stein DG. Neural progenitor cell transplants promote long-term functional recovery after traumatic brain injury. Brain Res. 2004;1026(1):11-22. doi:10.1016/j. brainres.2004.07.087.

46. Lepski G, Jannes CE, Wessolleck J, Kobayashi E, Nikkhah G. Equivalent neurogenic potential of wild-type and GFPlabeled fetal-derived neural progenitor cells before and after transplantation into the rodent hippocampus. Transplantation. 2011;91(4):390-7. doi: 10.1097/TP.0b013e3182063083.

47. Riess P, Zhang C, Saatman KE, Laurer HL, Longhi LG, Raghupathi R, Lenzlinger PM, Lifshitz J, Boockvar J, Neugebauer E, Snyder EY, McIntosh TK. Transplanted neural stem cells survive, differentiate, and improve neurological motor function after experimental traumatic brain injury. Neurosurgery. 2002;51(4):1043-52; discussion 52-4. DOI: 10.1227/01.NEU.0000027826.68845.CF.

48. Bakshi A, Shimizu S, Keck CA, Cho S, LeBold DG, Morales D, Arenas E, Snyder EY, Watson DJ, McIntosh TK. Neural progenitor cells engineered to secrete GDNF show enhanced survival, neuronal differentiation and improve cognitive function following traumatic brain injury. Eur J Neurosci. 2006;23(8):2119-34. doi: 10.1111/j.1460-9568.2006.04743.x

49. Hoane MR, Becerra GD, Shank JE, Tatko L, Pak ES, Smith M, Murashov AK. Transplantation of neuronal and glial precursors dramatically improves sensorimotor function but not cognitive function in the traumatically injured brain. J Neurotrauma. 2004;21(2):163-74. doi: $10.1089 / 089771504322778622$.

50. Becerra GD, Tatko LM, Pak ES, Murashov AK, Hoane MR. Transplantation of GABAergic neurons but not astrocytes induces recovery of sensorimotor function in the traumatically injured brain. Behav Brain Res. 2007;179(1):118-25. doi: 10.1016/j.bbr.2007.01.024.

51. Gao J, Prough DS, McAdoo DJ, Grady JJ, Parsley MO, Ma L, Tarensenko YI, Wu P. Transplantation of primed human fetal neural stem cells improves cognitive function in rats after traumatic brain injury. Exp Neurol. 2006;201(2):281-92. doi: 10.1016/j.expneurol.2006.04.039.

52. Gaillard A, Prestoz L, Dumartin B, Cantereau A, Morel F, Roger M, Jaber M. Reestablishment of damaged adult motor pathways by grafted embryonic cortical neurons. Nature Neurosci. 2007;10(10):1294-9. doi: 10.1038/nn1970.

53. Lima C, Pratas-Vital J, Escada P, Hasse-Ferreira A, Capucho C, Peduzzi JD. Olfactory mucosa autografts in human spinal cord injury: a pilot clinical study. J Spinal Cord Med. 2006;29(3):191-203; discussion 4-6. Available from: http:// www.ncbi.nlm.nih.gov/pmc/articles/PMC1864811/.

54. Lima C, Escada P, Pratas-Vital J, Branco C, Arcangeli CA, Lazzeri G, Maia CA, Capucho C, Hasse-Ferreira A, Peduzzi JD. Olfactory mucosal autografts and rehabilitation for chronic traumatic spinal cord injury. Neurorehabil Neural Repair. 2010;24(1):10-22. doi: 10.1177/1545968309347685.

55. Rabinovich SS, Seledtsov VI, Poveschenko OV, Senuykov VV, Taraban VY, Yarochno VI, Kolosov NG, Savchenko SA, Kozlov VA. Transplantation treatment of spinal cord injury patients. Biomed Pharmacother. 2003;57(9):428-33. doi: 10.1016/j.biopha.2003.05.001.

56. Blits B, Kitay BM, Farahvar A, Caperton CV, Dietrich WD, 
Bunge MB. Lentiviral vector-mediated transduction of neural progenitor cells before implantation into injured spinal cord and brain to detect their migration, deliver neurotrophic factors and repair tissue. Restorative Neurol Neurosci. 2005;23(5-6):313-24.

57. Xing J, Hou T, Jin H, Luo F, Change Z, Li Z, Xie Z, Xu $J$. Inflammatory microenvironment changes the secretory profile of mesenchymal stem cells to recruit mesenchymal stem cells. Cell Physiol Biochem. 2014;33(4):905-19. doi: $10.1159 / 000358663$.

58. Giusto E, Donega M, Cossetti C, Pluchino S. Neuro-immune interactions of neural stem cell transplants: from animal disease models to human trials. Exp Neurol. 2014;260:19-32. doi: 10.1016/j.expneurol.2013.03.009.

59. Bonig H, Becker PS, Schwebig A, Turner M. Biosimilar granulocyte-colony-stimulating factor for healthy donor stem cell mobilization: need we be afraid? Transfusion. 2015;55(2):430-9. doi: 10.1111/trf.12770.

60. Zimmermann S, Glaser S, Ketteler R, Waller CF, Klingmuller $\mathrm{U}$, Martens UM. Effects of telomerase modulation in human hematopoietic progenitor cells. Stem Cells. 2004;22(5):741-9. doi: 10.1634/stemcells.22-5-741.

61. Brann JH, Firestein SJ. A lifetime of neurogenesis in the olfactory system. Front Neurosci. 2014;8:182. doi: 10.3389/ fnins.2014.00182.

62. Chen C, Xiao SF. Induced pluripotent stem cells and neurodegenerative diseases. Neurosci Bull. 2011;27(2):10714. doi: 10.1007/s12264-011-1147-9.

63. Verma A, Verma N. Induced pluripotent stem cells and promises of neuroregenerative medicine. Neurol India. 2011;59(4):555-7. doi: 10.4103/0028-3886.84337.

64. Saito T, Yano F, Mori D, Kawata M, Hoshi K, Takato T, Masaki H, Otsu M, Eto K, Nakauchi H, Chung UI, Tanaka S. Hyaline cartilage formation and tumorigenesis of implanted tissues derived from human induced pluripotent stem cells. Biomed Res. 2015;36(3):179-86. doi: 10.2220/biomedres.36.179.

65. Panopoulos AD, Ruiz S, Izpisua Belmonte JC. iPSCs: induced back to controversy. Cell Stem Cell. 2011;8(4):347-8. doi: 10.1016/j.stem.2011.03.003.

66. Urabe M. Genetic manipulation of stem cells. Rinsho Ketsueki. 2015;56(8):1025-31. doi: 10.11406/rinketsu.56.1025.

67. Trosko JE. Induction of iPS cells and of cancer stem cells: the stem cell or reprogramming hypothesis of cancer? Anat Rec (Hoboken). 2014;297(1):161-73. doi: 10.1002/ar.22793. 